Supporting Information

\title{
Top-down preparation of active cobalt oxide catalyst
}

\author{
Yue Zhou ${ }^{\dagger,}$, Cun-Ku Dong ${ }^{\dagger}$, Li-Li Han ${ }^{\dagger}$, Jing Yang ${ }^{\dagger}$, Xi-Wen Du* ${ }^{*}{ }^{\dagger}$ \\ ${ }^{\dagger}$ Institute of New-Energy Materials, School of Materials Science and Engineering, Tianjin University, \\ Tianjin, 300072, China \\ ${ }^{\ddagger}$ Key Laboratory of Advanced Ceramics and Machining Technology, Ministry of Education, Tianjin \\ University, Tianjin, 300072, China \\ "Corresponding author: xwdu@tju.edu.cn
}

\section{Experimental Section}

Synthesis of $\mathrm{L}^{-} \mathrm{Co}_{3} \mathrm{O}_{4}$ nanoparticles: $\mathrm{L}^{-} \mathrm{CO}_{3} \mathrm{O}_{4}$ nanoparticles were synthesized by laser fragmentation of raw $\mathrm{CO}_{3} \mathrm{O}_{4}$ powders at room temperature. The laser source is a nanosecond pulsed Nd:YAG laser (Dawa-350 from Beamtech) with wavelength of $1064 \mathrm{~nm}$, pulse width $7 \mathrm{~ns}$, and power density $6 \times 10^{7} \mathrm{Wcm}^{-2}$. First, $1 \mathrm{mg}$ commercial $\mathrm{Co}_{3} \mathrm{O}_{4}$ powders were dissolved in $2 \mathrm{ml}$ deionized water, and then the suspension was stirred and irradiated by nanosecond laser for $20 \mathrm{~min}$ at room temperature, leading to the transformation into a brown colloid. Finally, the product was centrifuged at $15000 \mathrm{rpm}$ for $30 \mathrm{~min}$ and dried for 1 day.

Synthesis of $\mathrm{H}-\mathrm{CO}_{3} \mathrm{O}_{4}$ nanoparticles: $\mathrm{H}-\mathrm{Co}_{3} \mathrm{O}_{4}$ nanoparticles with the size similar to $\mathrm{L}_{-} \mathrm{Co}_{3} \mathrm{O}_{4}$ nanoparticles were synthesized as reported in literature. ${ }^{1} 2$ mmol of $\mathrm{Co}\left(\mathrm{CH}_{3} \mathrm{COO}\right)_{2} \cdot 4 \mathrm{H}_{2} \mathrm{O}$ was dissolved in a mixture of $2 \mathrm{ml}$ of $\mathrm{H}_{2} \mathrm{O}$ and $23 \mathrm{ml}$ of ethanol. Then $2.5 \mathrm{ml}$ of ammonia was added to the solution under stirring until it turned into dark blue. After that, the suspension was transferred into a $50 \mathrm{ml}$ autoclave and heated at $200{ }^{\circ} \mathrm{C}$ for 3 hours. The products were centrifuged at $15000 \mathrm{r} / \mathrm{min}$ for $10 \mathrm{~min}$, and then dried at room temperature for 1 day. 
Characterization: The structure and crystal phase were determined XRD (Siemens-Bruker D5000). TEM and high-resolution TEM was carried out by using JEOL 2100 Cryo microscope at an acceleration voltage of $200 \mathrm{kV}$ equipped with a field-emission gun and an Oxford INCA energy-dispersive X-ray spectroscopy (EDS) module. XPS analyses were conducted on a k-alpha Thermo fisher spectrometer (ThermoFisher Scientific). Raman spectra were measured on DXR Microscope using a laser with an excitation wavelength of $532 \mathrm{~nm}$ at laser powder of $4 \mathrm{~mW}$.

Electrochemical measurements: Electrochemical measurements were performed with a three-electrode cell configuration. A platinum sheet was used as the counter electrode while $\mathrm{Ag} / \mathrm{AgCl}$ electrode was used as the reference. 5 $\mathrm{mg}$ of catalysts, $7.5 \mathrm{mg}$ of carbon powders (Vulcan XC 72) and $30 \mu \mathrm{l}$ of $5 \mathrm{wt} \%$ Nafion solution were dispersed in $1 \mathrm{ml}$ water by $30 \mathrm{~min}$ sonication to form a homogeneous ink. Then the catalyst ink was dropped onto a carbon fiber and slowly dried to make a thin film working electrode with a catalysts loading mass of about $0.3 \mathrm{mg} / \mathrm{cm}^{2}$. The reference electrode was calibrated in $\mathrm{O}_{2}$-saturated 1 $\mathrm{M} \mathrm{KOH}$. CV curve was recorded between $1.0 \mathrm{~V}$ and $1.55 \mathrm{~V}$ at a scan rate of 5 $\mathrm{mV} / \mathrm{s}$, and the same scan rate was applied for LSV. Furthermore, all linear sweep curves were corrected with iR-compensation. The potentials reported in our work were calculated with reference to the reversible hydrogen electrode calibration $\mathrm{E}(\mathrm{RHE})=\mathrm{E}(\mathrm{Ag} / \mathrm{AgCl})+1.004 \mathrm{~V}($ see Figure S9)

Calculation method: All periodical $D F T+U$ calculations were performed within the framework of the generalized gradient approximation (GGA) using the PBE exchange-correlation functional, as implemented in Vienna ab initio simulation package $(\mathrm{VASP})^{2}$. The projector augmented plane wave (PAW) method ${ }^{3,4}$ was employed for treating the electron-ion interactions; the electron exchange-correlation effects were accounted. The plane wave cut off of 550 $\mathrm{eV}$ and a standard Monkhorst-Pack grid with sampling mesh of $4 \times 4 \times 1$ were adopted for slab calculations. 


\section{Characterizations of $\mathrm{Co}_{3} \mathrm{O}_{4}$ catalysts.}

(a)

(b)
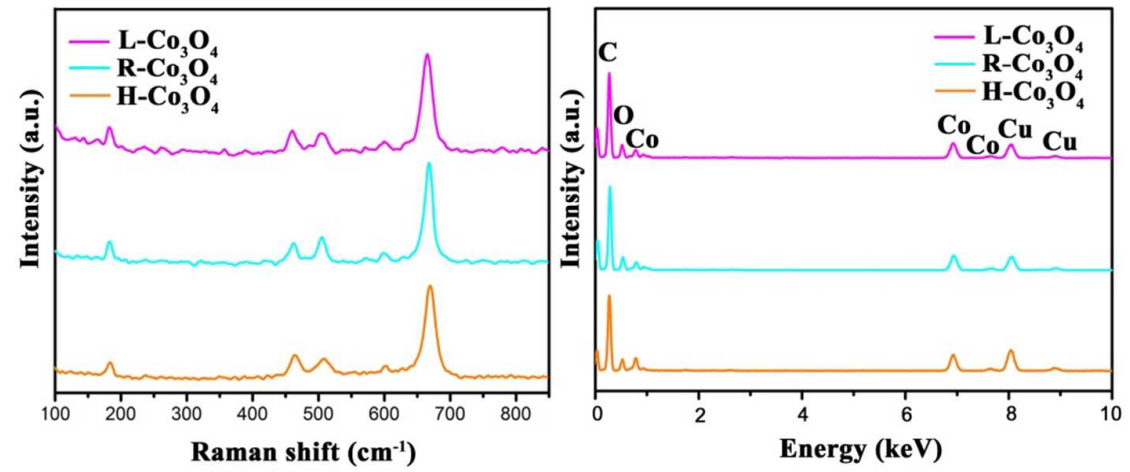

Figure S1. (a) Raman spectra and (b) EDS profiles of $\mathrm{L}-\mathrm{CO}_{3} \mathrm{O}_{4}, \mathrm{R}-\mathrm{Co}_{3} \mathrm{O}_{4}$ and $\mathrm{H}-\mathrm{CO}_{3} \mathrm{O}_{4}$.

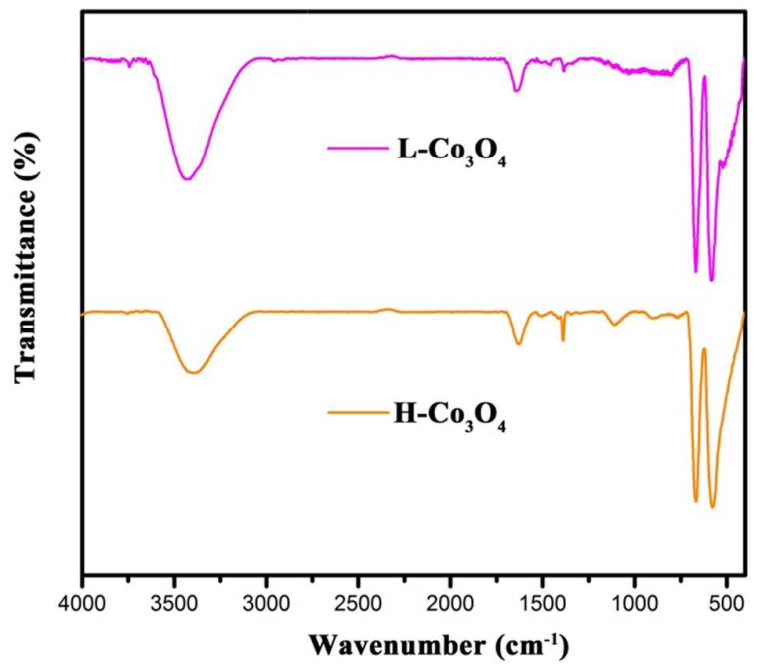

Figure S2. FTIR spectra for $\mathrm{L}-\mathrm{Co}_{3} \mathrm{O}_{4}$ and $\mathrm{H}-\mathrm{Co}_{3} \mathrm{O}_{4}$. The bands at ca. $3400 \mathrm{~cm}^{-1}$ and $1620 \mathrm{~cm}^{-1}$ belong to $\mathrm{OH}^{-}$groups absorbed on the surface. The absorptions at ca. $1402 \mathrm{~cm}^{-1}$ and $1109 \mathrm{~cm}^{-1}$ are characteristics as acetate ions from the precursor cobalt acetate. The two strong bands centered at ca. $570 \mathrm{~cm}^{-1}$ and $665 \mathrm{~cm}^{-1}$ were assigned to $\mathrm{v}(\mathrm{Co}-\mathrm{O})$ modes of $\mathrm{Co}_{3} \mathrm{O}_{4}{ }^{5}$ 


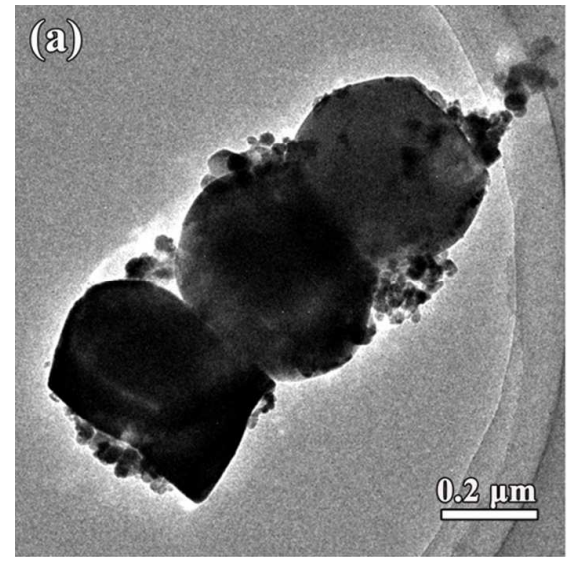

(b)

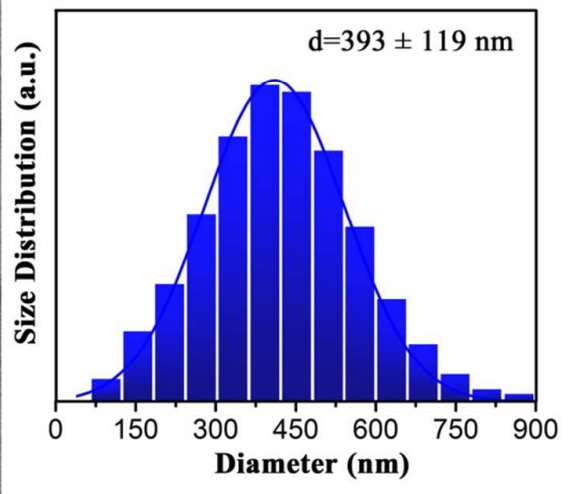

Figure S3. (a) TEM image and (b) Size distribution of $\mathrm{R}-\mathrm{Co}_{3} \mathrm{O}_{4}$.
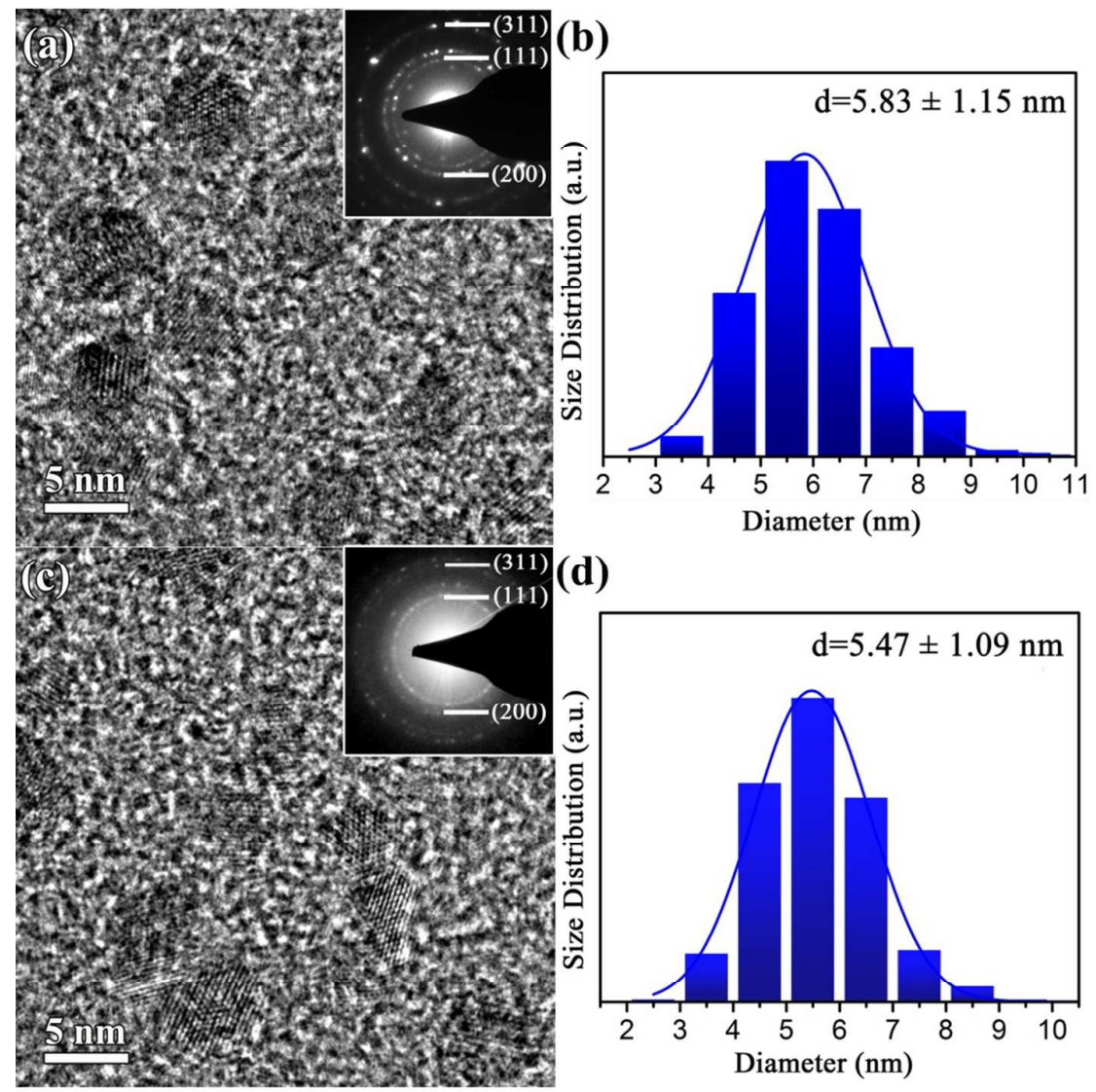

(d)

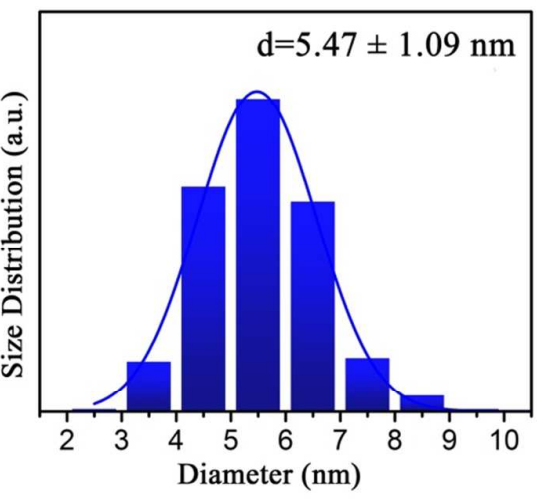

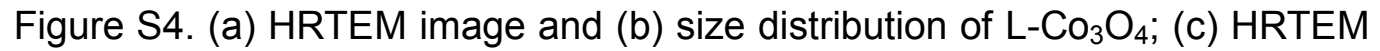
image and (d) size distribution of $\mathrm{H}-\mathrm{CO}_{3} \mathrm{O}_{4}$. The insets in (a) and (c) are SAED patterns. 


\section{Electrochemical characterizations of $\mathrm{Co}_{3} \mathrm{O}_{4}$ catalysts.}

Table S1. The properties of $\mathrm{Co}_{3} \mathrm{O}_{4}$ catalysts reported in literature.

\begin{tabular}{|c|c|c|c|c|}
\hline Material & $\begin{array}{c}\text { Overpotential } \\
\text { at } \\
10 \mathrm{~mA} / \mathrm{cm}^{2}(\mathrm{mV})\end{array}$ & $\begin{array}{c}\text { Tafel } \\
\text { (mV/dec) }\end{array}$ & $\begin{array}{l}\text { Stability } \\
\text { (h) }\end{array}$ & Ref \\
\hline $\mathrm{Co}_{3} \mathrm{O}_{4}$ nanowires & 400 & 72 & $\sim 1.7$ & 6 \\
\hline $\mathrm{Co}_{3} \mathrm{O}_{4} \mathrm{NPs}$ & 430 & $\sim 100$ & & 7 \\
\hline $\mathrm{Co}_{3} \mathrm{O}_{4} \mathrm{NPs} /$ graphene & 350 & 56 & $\sim 10$ & 8 \\
\hline $\mathrm{Co}_{3} \mathrm{O}_{4} \mathrm{NPs} / \mathrm{MWCNTs}$ & 380 & $\sim 116$ & - & 9 \\
\hline $\mathrm{Co}_{3} \mathrm{O}_{4} / \mathrm{N}-\mathrm{rmGO}$ & 310 & 67 & 2.8 & 10 \\
\hline $\mathrm{Co}_{3} \mathrm{O}_{4} @ G C N$ & 270 & 76 & 10 & 11 \\
\hline $\mathrm{L}-\mathrm{Co}_{3} \mathrm{O}_{4} \mathrm{NPs}$ & 294 & 74 & 75 & this work \\
\hline
\end{tabular}

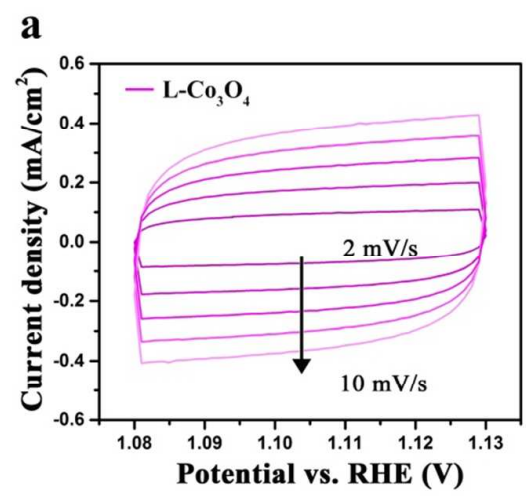

b
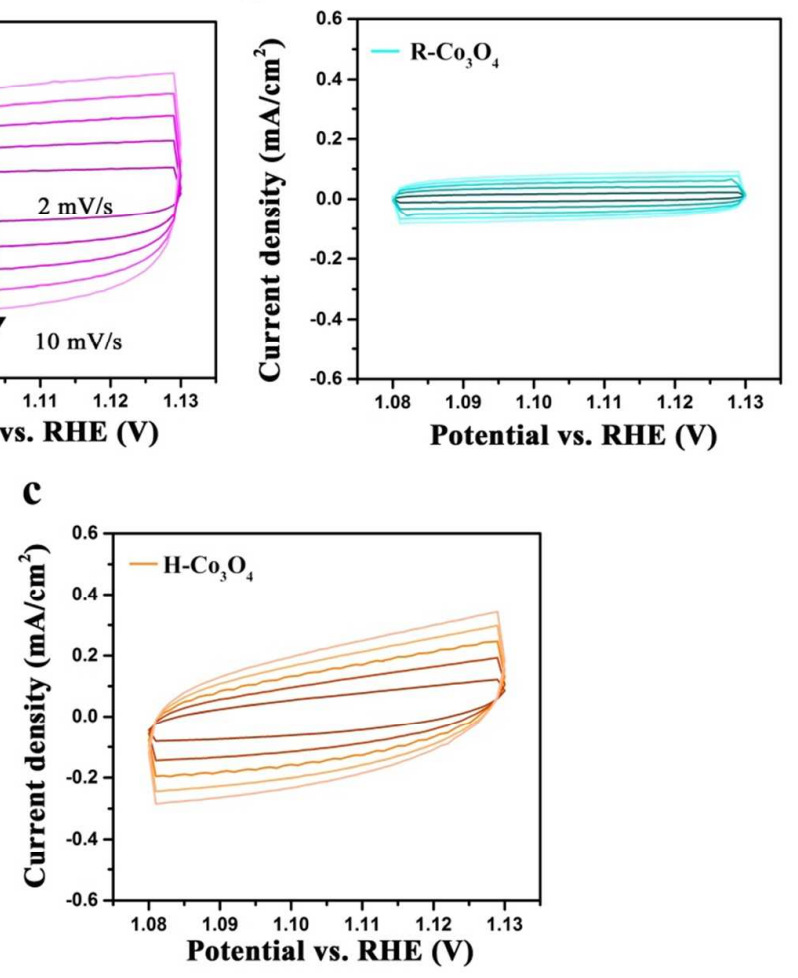

Figure S5. Cyclic voltammograms of (a) $\mathrm{L}-\mathrm{Co}_{3} \mathrm{O}_{4}$, (b) $\mathrm{R}-\mathrm{Co}_{3} \mathrm{O}_{4}$ and (c) $\mathrm{H}-\mathrm{Co}_{3} \mathrm{O}_{4}$ measured at scan rates from 2 to $10 \mathrm{mV} / \mathrm{s}$. 


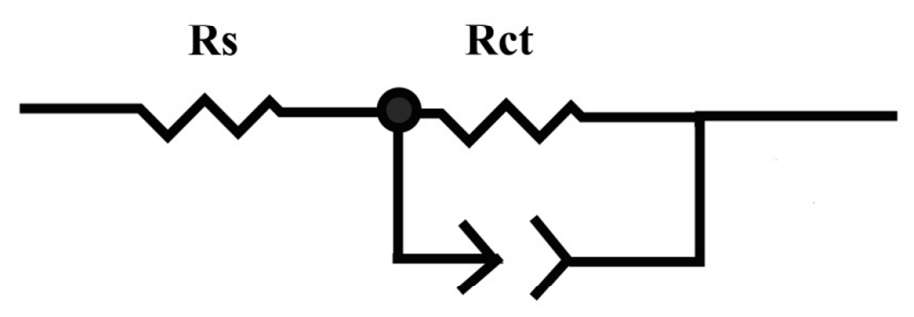

Figure S6. Equivalent circuit model for electrochemical impedance tests. Rs, Rct and CPE represent the resistance of electrolyte, the resistance of charge transfer, and constant-phase element, respectively.

3. XPS analysis of $\mathrm{Co}_{3} \mathrm{O}_{4}$ catalysts.

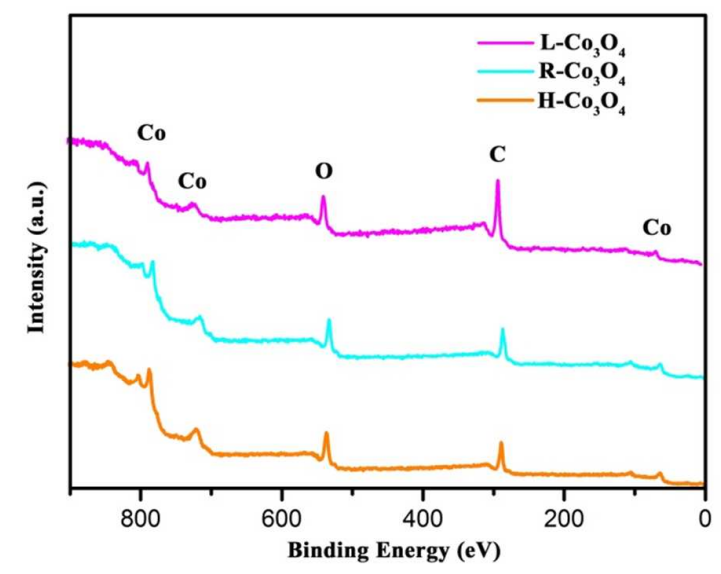

Figure S7. XPS survey spectrum of $\mathrm{L}-\mathrm{Co}_{3} \mathrm{O}_{4}, \mathrm{R}-\mathrm{Co}_{3} \mathrm{O}_{4}$ and $\mathrm{H}-\mathrm{Co}_{3} \mathrm{O}_{4}$.

Table S2. Summary of area percentages of different oxygen species obtained from the deconvoluted spectra

\begin{tabular}{lccc}
\hline & \multicolumn{3}{c}{ \% area (0 1s) } \\
\hline Sample & $\mathrm{O}_{\mathrm{L}}$ & $\mathrm{O}_{V}$ & Omw \\
$\mathrm{L}-\mathrm{Co}_{3} \mathrm{O}_{4}$ & 37.15 & 36.22 & 26.63 \\
$\mathrm{R}-\mathrm{Co}_{3} \mathrm{O}_{4}$ & 67.98 & 20.40 & 11.62 \\
$\mathrm{H}-\mathrm{Co}_{3} \mathrm{O}_{4}$ & 48.03 & 31.35 & 20.61 \\
\hline
\end{tabular}




\section{Calculation on the adsorption energy of $\mathrm{H}_{2} \mathrm{O}$ molecule on surfaces with and without vacancies.}

All DFT calculations were performed using Vienna ab initio simulation package (VASP) code. The projector augmented plane wave (PAW) method was employed for treating the electron-ion interactions; the electron exchange-correlation effects were accounted within the framework of the generalized gradient approximation (GGA) using the PBE exchange-correlation functional. DFT+U method was employed to describe the $d-d$ orbital interaction with the $U$ value of 3.7. The full optimization of the system achieved with the convergence criterion for energy and maximum force exerted on each atom set to $10^{-4} \mathrm{eV}$ and $0.01 \mathrm{eV} / \AA$, respectively. The plane wave cut off of $550 \mathrm{eV}$ and a standard Monkhorst-Pack grid with sampling mesh of $4 \times 4 \times 1$ were adopted for slab calculations. The bulk $\mathrm{Co}_{3} \mathrm{O}_{4}$ unit cell was obtained by optimizing the $(1 \times 1 \times 1)$ cell. Perfect (110) surface of $\mathrm{Co}_{3} \mathrm{O}_{4}$ slab was modeled using five layer symmetric slabs with vacuum widths of 15 $\AA$. The $\mathrm{Co}_{3} \mathrm{O}_{4}$ (110) slab with one oxygen vacancy was constructed by deleting a surface oxygen atom. The two bottom layers were fixed while the topmost three layers were fully relaxed. For the OER system, $\mathrm{H}_{2} \mathrm{O}$ adsorption on $\mathrm{Co}_{3} \mathrm{O}_{4}$ and vacant $\mathrm{Co}_{3} \mathrm{O}_{4}$ (110) slabs were constructed by placing a $\mathrm{H}_{2} \mathrm{O}$ molecule above the relaxed layers. 
(a)

(c)
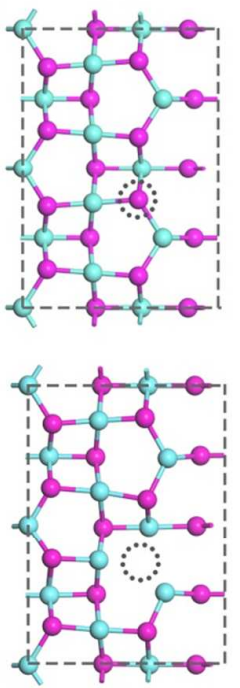

(b)

(d)
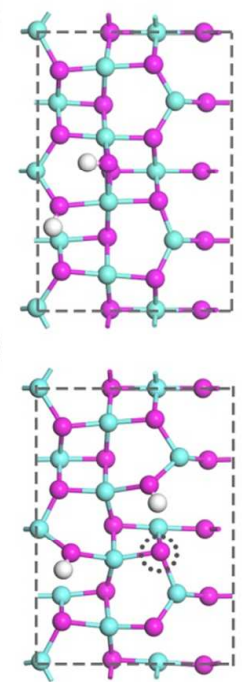

Figure S8. Top-view of $\mathrm{Co}_{3} \mathrm{O}_{4}$ (110) surface for DFT calculation. Perfect $\mathrm{Co}_{3} \mathrm{O}_{4}$ (110) surface (a) before and (b) after the adsorption of $\mathrm{H}_{2} \mathrm{O}$ molecule. $\mathrm{Co}_{3} \mathrm{O}_{4}$ (110) surface with an oxygen vacancy (c) before and (d) after the adsorption of $\mathrm{H}_{2} \mathrm{O}$ molecule.

\section{Calculation of temperature rise of $\mathrm{Co}_{3} \mathrm{O}_{4}$ nanoparticles under laser irradiation.}

The temperature rise can be calculated according to the following equation

$$
\mathrm{n} * \mathrm{~J} * \mathrm{C}_{\mathrm{abs}}^{1064 \mathrm{~nm}}(\mathrm{D})=\mathrm{C}_{\mathrm{p}} * \Delta \mathrm{T}+\Delta \mathrm{H}_{\mathrm{m}}+\Delta \mathrm{H}_{\mathrm{b}}
$$

where, $\mathrm{n}$ represent the number of $\mathrm{Co}_{3} \mathrm{O}_{4}$ nanoparticle in $1 \mathrm{~mol} \mathrm{Co}_{3} \mathrm{O}_{4}$ powders, $C_{\text {abs }}^{1064 \mathrm{~nm}}$ indicated (D) per particle absorption cross section @ 1064 $\mathrm{nm}$ (laser wavelength) for particle size about $400 \mathrm{~nm}$. J demonstrated the laser influence energy density. The heat capacity $\mathrm{C}_{\mathrm{p}}$ of bulk $\mathrm{Co}_{3} \mathrm{O}_{4}$, melting temperature $T_{\mathrm{ml}}$, boiling temperature $\mathrm{T}_{\mathrm{bl}}$, melting heat $\Delta \mathrm{H}_{\mathrm{m}}$ and boiling heat $\Delta \mathrm{H}_{\mathrm{b}}$ were all taken from Lange ${ }^{12}$.

\section{Calibration of reference electrode.}




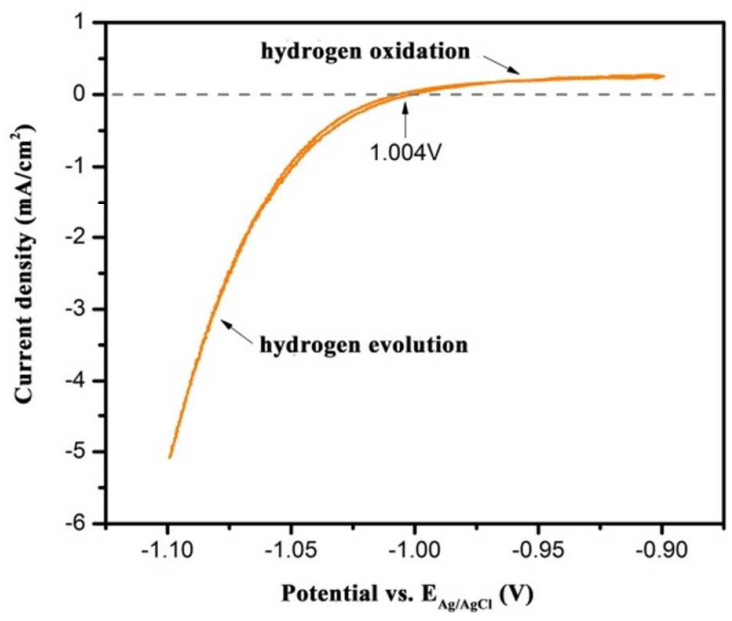

Figure S9. $\mathrm{Ag} / \mathrm{AgCl}$ reference used in electrocatalysis measurements were calibrated vs RHE. The calibration was performed in hydrogen saturated electrolyte with a Pt sheet as the working electrode. Cyclic voltammetry ran at a scan rate of $5 \mathrm{mV} / \mathrm{s}$, and the average of the two potentials at which the current value was zero was taken as the thermodynamic potential. So the $1 \mathrm{M}$ $\mathrm{KOH}, \mathrm{E}(\mathrm{RHE})=\mathrm{E}(\mathrm{Ag} / \mathrm{AgCl})+1.004 \mathrm{~V}$.

\section{Reference}

1. Dong, Y.; He, K.; Yin, L.; Zhang, A. Nanotechnology 2007, 18, 435602 (1-6).

2. Kresse .G , Furthmiiller .J , Comp. Mater. Sci. 1996, 6, 15-50.

3. Blöchl, P. E. Phys. Rev. B. 1994, 50, 17953-17979.

4. Kresse, G. Phys. Rev. B. 1999. 59, 1758-1775.

5. Shi, N.; Cheng, W.; Zhou, H.; Fan, T.; Niederberger, M. Chem. Commun. 2015, 51, 1338-1340.

6. Wang, Y.; Zhou, T.; Jiang, K.; Da, P.; Peng, Z.; Tang, J.; Kong, B.; Cai, W.-B.; Yang, Z.; Zheng, G. Adv Energy Mater. 2014, 4 ,1400696 (1-7).

7. Jin, H.; Wang, J.; Su, D.; Wei, Z.; Pang, Z.; Wang, Y. J. Am. Chem. Soc. 2015, 137, 2688-2694.

8. Zhao, Y.; Chen, S.; Sun, B.; Su, D.; Huang, X.; Liu, H.; Yan, Y.; Sun, K.; Wang, G. Sci. Rep. 2015, 5, 7629 (1-7).

9. Li, X.; Fang, Y.; Lin, X.; Tian, M.; An, X.; Fu, Y.; Li, R.; Jin, J.; Ma, J. J. Mater. Chem. A 2015, 3, 17392-17402.

10.Liang, Y.; Li, Y.; Wang, H.; Zhou, J.; Wang, J.; Regier, T.; Dai, H. Nat. Mater. 2011, 10, 780-786.

11. Tahir, M.; Mahmood, N.; Zhang, X.; Mahmood, T.; Butt, F. K.; Aslam, I.; 
Tanveer, M.; Idrees, F.; Khalid, S.; Shakir, I.; Yan, Y.; Zou, J.; Cao, C.; Hou, Y. Nano Res. 2015, 8, 3725-3736.

12. Speight, J. G. Lange's Handbook of Chemistry , McGraw-Hill, New York, NY, USA 2004. 